\title{
Climate change and marine ecosystems
}

\author{
Francisco P. Chavez ${ }^{1}$ \\ Monterey Bay Aquarium Research Institute, Moss Landing, CA 95039
}

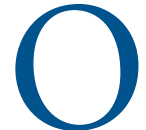
ne of the most pressing questions of the day is how natural systems will respond to future changes in climate. By looking to the past we know that climate-driven phenomena have resulted in large changes to marine ecosystems; dramatic shifts in the abundance of fish off the coast of Peru occurred at the end of the Little Ice Age (LIA) (1). These shifts were linked to a southward migration in the mean position of the InterTropical Convergence Zone (ITCZ). Frequent flyers know the ITCZ as a region of increased turbulence found between the northern and southern hemispheres; it is a region of low atmospheric pressure that rings the globe and is often referred to as the meteorological equator, albeit mostly north of it. As the polar ice caps expanded during the LIA, the mean position of the ITCZ was pushed southward of its present location $(1,2)$, shutting down the Walker circulation in the Pacific, one of the drivers of increased productivity off the coast of Peru. The abundant concentrations of small pelagic fish that in the present day make Peru the most productive region in the world in terms of fish (3) were hardly evident in sediment cores during the LIA but returned dramatically when conditions warmed (1). A similar migration of the ITCZ occurs seasonally when during the boreal winter the mean position is found $5-10^{\circ}$ farther south than during boreal summer. The opposite northward migration is predicted during a warmer world (2). In PNAS, Taylor et al. (4) describe the response of a marine ecosystem in the marginal southern Caribbean Sea to present-day northward migrations of the ITCZ (Fig. 1). Using $15 \mathrm{y}$ of repeated measurements, they show how the upwelling-favorable trade winds have diminished by the northward migration of the ITCZ, warming the ocean and decreasing primary productivity with effects cascading through the local ecosystem.

Coastal upwelling is a process by which waters from 50 to $100 \mathrm{~m}$ depth are brought to the surface through the combined effects of wind, the earth's rotation, and a coastline. The upwelled waters typically originate from below the thermocline that separates the warm surface from the cool deep ocean rich in nutrients. When the deeper compost-like waters are brought to the surface and come in contact with sunlight, photosynthesis is stimulated and rich ecosystems develop (Fig. 1). The most prominent coastal upwelling ecosystems are

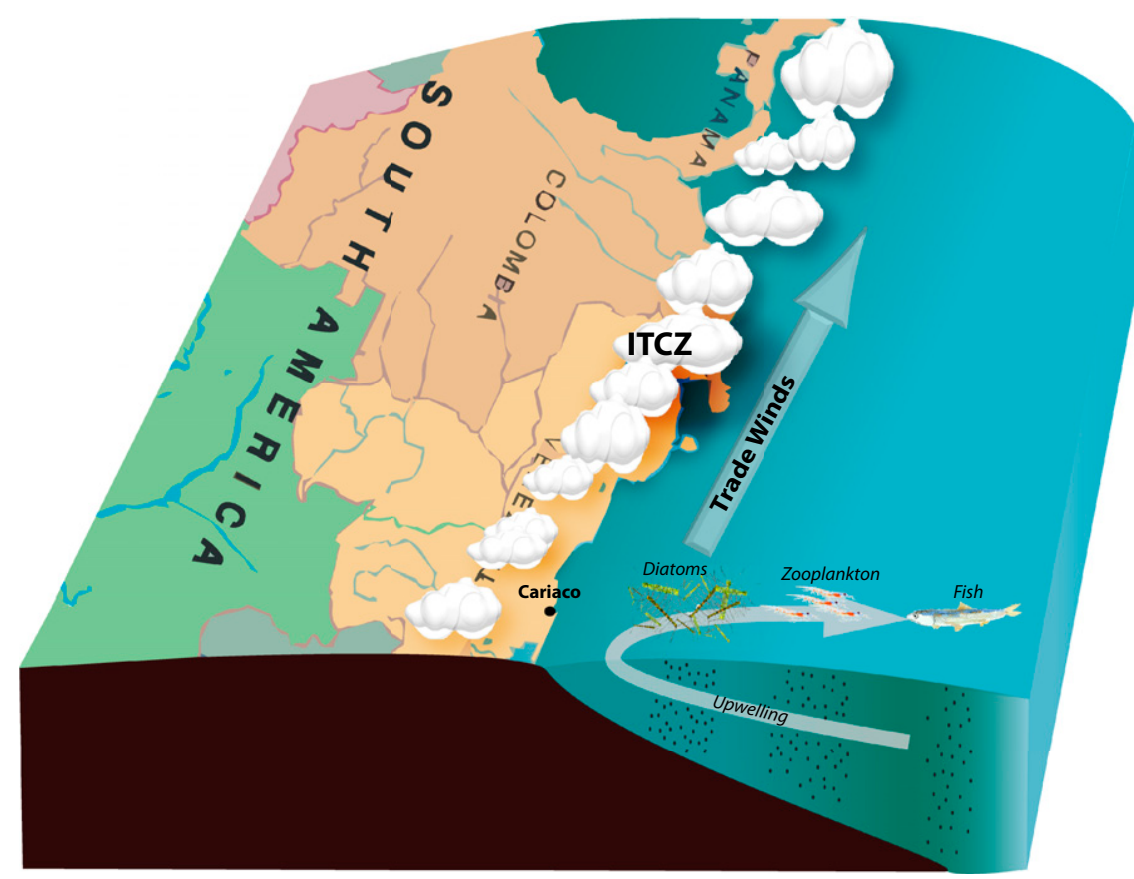

Fig. 1. Schematic showing the annual southward position of the InterTropical Convergence Zone (ITCZ), associated trade winds that drive coastal upwelling in the southeast Caribbean off Venezuela, and the rich ecosystem that develops. The average annual position of the ITCZ has been moving northward since the Little Ice Age at an average rate of $1.5 \mathrm{~km} / \mathrm{y}(2)$, a rate that may have accelerated recently (4). As the average southward position of the ITCZ moves north over the Caribbean, the winds that drive coastal upwelling weaken, the coastal ocean warms, and primary productivity decreases with cascading effects through the entire ecosystem (3). The leakage of organic carbon resulting from primary production and the pelagic food web into the ocean's interior acts to sequester atmospheric carbon dioxide to the deep ocean; enigmatic results from the Cariaco time series show that there are still uncertainties about how this biological pump of carbon operates and how it will respond to future changes in climate.

associated with the eastern boundaries of ocean basins in regions like Peru, Chile, California, northwest Africa, and Benguela. A similar upwelling ecosystem develops in the southeast Caribbean off Venezuela, driven by an intensification of trade winds during the annual southward migration of the ITCZ. Like other coastal upwelling ecosystems, it is characterized by high primary production, is diatom dominated, and results in abundant concentrations of small pelagic fish like anchovy or sardine. Diatoms are small microscopic algae that double on the order of once per day and were once referred to by Henry Bigelow (5) as "all fish is diatoms." The fast-growing microscopic photosynthetic plankton that are the forests of the oceans require high-frequency measurement over extended periods to determine ecosystem change. Taylor et al. (4) are able to clearly document the relations between the decrease in upwelling-favorable winds driven by the northward migration of the ITCZ, a warmer more stratified ocean, and lower levels of primary production and sardines.

Although some of the results presented are straightforward, others are counterintuitive. Coastal upwelling ecosystems have been described by Margalef (6) as leaky in that a significant fraction of the organic matter resulting from primary production sinks below the euphotic zone to the twilight zone and the sediments. One would predict that declining primary production would result in a decrease of the organic matter export; however, Taylor et al. (4) report increases in this flux. Taylor et al. hypothesize that this increase is a result of changes throughout the different trophic levels and their interactions. This enigmatic part of the story is not yet complete, requiring further study; understanding

Author contributions: F.P.C. wrote the paper. The author declares no conflict of interest. See companion article on page 19315

1'E-mail: chfr@mbari.org 
how this "biological pump" of carbon operates is critical to elucidating the changing role of marine ecosystems in the global carbon cycle (Fig. 1). A second surprise that Taylor et al. (4) find is punctuated step function decreases in the abundance of critical taxonomic groups. Whereas sea surface temperature has increased and primary production decreased steadily, the abundance of the microscopic primary producers (including diatoms, dinoflagellates, and coccolithophorids) and sardines show a stepwise decrease close to

1. Gutiérrez D, et al. (2009) Rapid reorganization in ocean biogeochemistry off Peru towards the end of the Little Ice Age. Biogeosciences 6:835-848.

2. Sachs JP, et al. (2009) Southward movement of the Pacific intertropical convergence zone AD 1400-1850. Nat Geosci 2:519-525.

3. Chavez FP, Bertrand A, Guevara R, Soler P, Csirke J (2008) The northern Humboldt Current System: Brief
2005. These punctuated changes highlight nonlinear relations between physics and biology and the challenges associated with predicting ecosystem change.

Time-series sites like the one in the southeastern Caribbean are rare; there are only a handful sprinkled around the world (7). These time series demonstrate that presently regions are responding quite differently to changes in climate. For example, as might be predicted by the northward migration of the ITCZ, biological productivity off Peru has been

history, present status and a view towards the future. Prog Oceanogr 79:95-105.

4. Taylor GT, et al. (2012) Ecosystem responses in the southern Caribbean Sea to global climate change. Proc Natl Acad Sci USA 109:19315-19320.

5. Bigelow HB (1926) Plankton of the offshore waters of the Gulf of Maine. Bulletin of the Bureau of Fisheries (Government Printing Office, Washington, DC), Vol XL, 509 pp. increasing. Given the length of these time series (15-25 y), it remains unclear whether observed changes are driven by low-frequency climate variability associated with phenomena like the Pacific Decadal Oscillation or the Atlantic Multidecadal Oscillation or whether they are driven by longer-term anthropogenic forcing (7). This deficiency could be addressed with a global-scale effort to increase the number of stations and fully integrate the information.

6. Margalef $R$ (1978) What is an upwelling ecosystem? Upwelling Ecosystems, eds Boje R, Tomczak M (Springer, Berlin), pp 12-14.

7. Chavez FP, Messié M, Pennington JT (2011) Marine primary production in relation to climate variability and change. Annu Rev Mar Sci 3:227-260 